\title{
Industrial waste utilization in the panels production for high buildings facade and socle facing
}

\author{
Irina Vitkalova ${ }^{1}$, Anastasiya Torlova ${ }^{1}$, Evgeniy Pikalov $^{1, *}$, and Oleg Selivanov ${ }^{1}$ \\ ${ }^{1}$ Vladimir State University named after A.G. and N.G. Stoletovs, 600000 Vladimir, Russia
}

\begin{abstract}
The research presents comprehensive utilization of such industrial waste as galvanic sludge, broken window glass as functional additives for producing ceramics for facade and socle paneling in high-rise construction. The basic charge component is low-plasticity clay, which does not allow producing high-quality products if used without any functional additives. The application of the mentioned above components broadens the resource base, reduces production cost and the mass of the products in comparison with the currently used facing ceramics. The decrease of product mass helps to reduce the load on the basement and to use ceramic material in high-rise construction more effectively. Additional advantage of the developed composition is the reducing of production energy intensity due to comparatively low pressing pressure and firing temperature thus reducing the overall production cost. The research demonstrates the experimental results of determining density, compressive strength, water absorption, porosity and frost resistance of the produced ceramic material. These characteristics prove that the material can be applied for high buildings outdoor paneling. Additional research results prove ecologic safety of the produced ceramic material.
\end{abstract}

\section{Introduction}

Buildings facing is well known to be used for protecting facades and socles against negative environmental impacts such as temperature drops, snow and rain falls. Besides buildings paneling is significant for creating beautiful design and presentable appearance.

Nowadays a great variety of materials is used for buildings facing. The choice of materials depends on operating conditions, shape and building height, design solutions and facing materials price.

Ceramics is one of the most ancient known materials, but today it still remains very popular. Its principle advantages are its durability, reliable protection against environmental impact and ecological safety. Moreover ceramics is characterized by a wide assortment of color and texture, fire resistance and safety, it does not fade with the time.

Building facades and socles facing with ceramics is widely and successfully applied both in low and high-rise construction. Speaking about tall building facing, ceramics

\footnotetext{
* Corresponding author: evgeniy-pikalov@,mail.ru
} 
advantages include its stable resistance towards temperature drops and almost any wind pressure, which gets stronger with the buildings height. The most effective way is to produce large area panels because it simplifies and hastens their mounting. In case with socles it is better to use special adhesive compositions, and for facades facing it is advisable to mount them on the purlins according to the ventilated facade system. Like any other material ceramics has several disadvantages including comparatively big mass, high price, fragility and brittleness. The last two features cause the requirement of careful mounting of the panels.

The research objective is to develop the charge composition for ceramic facing material production providing lower production cost and mass in comparison with the existing analogues (terracotta tiles, clinker and porcelain stoneware) and at the same time retaining its strength and other performance characteristics for using the material in the facing of high buildings construction.

The objective is suggested to be reached by using low cost raw materials and decrease of pressing pressure and firing temperature. Most facing ceramic materials are produced using high plasticity clays. Our research suggests using low plasticity clay and additionally secondary raw materials serving as functional additives but not as cheap fillers.

Basing on the previous experiments [1] the authors stated that ecologically safe ceramic materials can be produced adding 2.5 mass \% of galvanic sludge and 2 mass $\%$ of boric acid. Moreover boric acid stipulates the formation of vitreous phase at firing increasing the strength properties and complicating the migration of heavy metals, contained in the galvanic sludge, into the environment. In this connection a special interest ranks the boric acid replacement in the charge composition directly by the cullit, which is also a waste material.

Using secondary raw materials will stipulate cost reduction and quality improvement of the ceramic facing panels, on the one hand and the possibility of comprehensive waste utilization on the other.

\section{Materials and Methods}

The experiments during the research process were carried out using raw materials available in the Vladimir region and regarding regional peculiarities.

The basic component of the developed charge was the clay from Suvorotskoe field in Vladimir region with the following composition (mass \%): $\mathrm{SiO}_{2}=67,5 ; \mathrm{Al}_{2} \mathrm{O}_{3}=10,75$; $\mathrm{Fe}_{2} \mathrm{O}_{3}=5,85 ; \mathrm{CaO}=2,8 ; \mathrm{MgO}=1,7 ; \mathrm{K}_{2} \mathrm{O}=2,4 ; \mathrm{Na}_{2} \mathrm{O}=0,7$. The presence of aluminum, calcium and magnesium oxides testified of the low clay plasticity [1], plasticity rate amounted 5.2, determined by the standard method, and hence in compliance with GOST 9169-75 the researched clay referred to low plasticity group. Consequently the production of high quality products from this clay without introducing any functional additives is impossible though its application may help developing regional raw materials base and reduce production cost.

The second component of the charge composition is galvanic sludge (moisture $60-70 \%$ mass \%) received after chemical treatment of electroplating effluents at machine building enterprises [1]. Galvanic sludge contained the following chemicals (mass \%): $\mathrm{Zn}(\mathrm{OH})_{2} \approx$ $11,3 \% ; \mathrm{SiO}_{2} \approx 7,08 \% ; \mathrm{Ca}(\mathrm{OH})_{2} \approx 16,52 \% ; \mathrm{Cr}(\mathrm{OH})_{3} \approx 9,31 \% ;\left(\mathrm{Fe}^{2+}\right) \mathrm{Cr}_{2} \mathrm{~S}_{4} \approx 4,17 \% ; \mathrm{CaCO}_{3}$ $\approx 40,25 \% ; \mathrm{CaO} \approx 3,45 \% ; \mathrm{ZnO} \approx 2,41 \% ; \mathrm{Cu}(\mathrm{OH})_{2} \approx 2,38 \% ; \mathrm{Ni}(\mathrm{OH})_{2} \approx 2,62 \% ; \mathrm{Mn}(\mathrm{OH})_{2} \approx$ $0,64 \% ; \mathrm{Pb}(\mathrm{OH})_{2} \approx 0,14 \%$. The relatively big number of compounds, containing zinc, chromium, nickel and copper as hydroxides, prove of galvanic sludge toxicity [1]. According to the public data $[1,2]$ nowadays no technology provides the problem solution of galvanic sludge accumulation in the Vladimir region, therefore the development of their utilization method is very vital. The application of galvanic sludge in the construction 
materials production including building ceramics might become a real solution of the problem.

Another charge component is window glass cullit of the following composition (mass \%): $\mathrm{SiO}_{2}=73,5 ; \mathrm{CaO}=7,4 ; \mathrm{MgO}=1,9 ; \mathrm{Na}_{2} \mathrm{O}=11,1 ; \mathrm{K}_{2} \mathrm{O}=5,2 ; \mathrm{Al}_{2} \mathrm{O}_{3}=0,9$. Glass cullit in Vladimir region is a result of local glass production enterprises operation and household consumption, which is accumulated in the region. This waste is not completely processed by the enterprises because of the composition diversity [3] and sources, therefore it is piled in big amounts (up to $10 \%$ of the total waste) in storage and waste disposals [4]. Consequently its utilization deserves special attention.

Boric acid of B type, 2-nd class (GOST 18704-78) was introduced into the charge as an additional component which increases ceramic material strength and prevents heavy metals migration into the environment $[1,2]$.

The samples were made according to the following technology: clay and galvanic sludge were dried to constant mass and then grinded. Further research was conducted using fraction with particles size less than $0.63 \mathrm{~mm}$. Afterwards raw components were mixed, moistened for reaching mold moisture of 8 mass \%. The cube samples with $50 \mathrm{~mm}$ side were formed under the pressing pressure of $15 \mathrm{MPa}$ from the received charge and then fired at the temperature of $1050{ }^{\circ} \mathrm{C}$. The samples of the researched compositions were made by series of 3 samples each.

To assess the impact additives composition of the charge in the samples according to standard methods for ceramic material the following basic characteristics were determined: density $\left(\rho, \mathrm{kg} / \mathrm{m}^{3}\right)$ compressive strength $\left(\sigma_{\mathrm{cmp}}, \mathrm{MPa}\right)$, porosity $(\mathrm{P}, \%)$, water absorption (WA, \%) and frost resistance (FR, cycles).

As the used galvanic sludge refers to 2-3 hazard category [1] additional research was carried out to prove ecologic safety of the produced ceramic material using the method of Daphnia magna Straus under the impact of toxic substances in the daily water extraction of the researched samples [5].

Scanning electron microscope REM Quanta 200 3D was used to the analysis and assessment of the samples structure.

\section{Results}

At the first stage of the research it was decided to increase galvanic sludge amount in the previously developed composition of the charge [1] from 2.5 to 5 mass $\%$, to exclude boric acid and to introduce from 10 to 30 mass \% of glass cullit in every 5 mass \%. The results of the ceramic properties determination based on the researched compositions are demonstrated in figures 1 and 2 .

The presented data demonstrates that the strength properties and frost resistance of the ceramic material increase but porosity and water absorption decrease with the enhanced content of glass cullit amount in the charge composition. It can be described by the increased amount of vitreous phase at firing, which not only fills the interstices between the ceramic particles in the material, but also serves as a binder between them thus forming a firm frame, which is proved by the images made by REM and demonstrated in figure 3 . However during samples toxicity tests over $50 \%$ Daphnias deaths (Daphnia magna Straus) were observed in all the cases during first 50-75 hours. That is why it was decided to introduce boric acid into the charge in the amount of 2.5 and 5 mass \%, thus decreasing ceramic material toxicity with galvanic sludge [1]. 


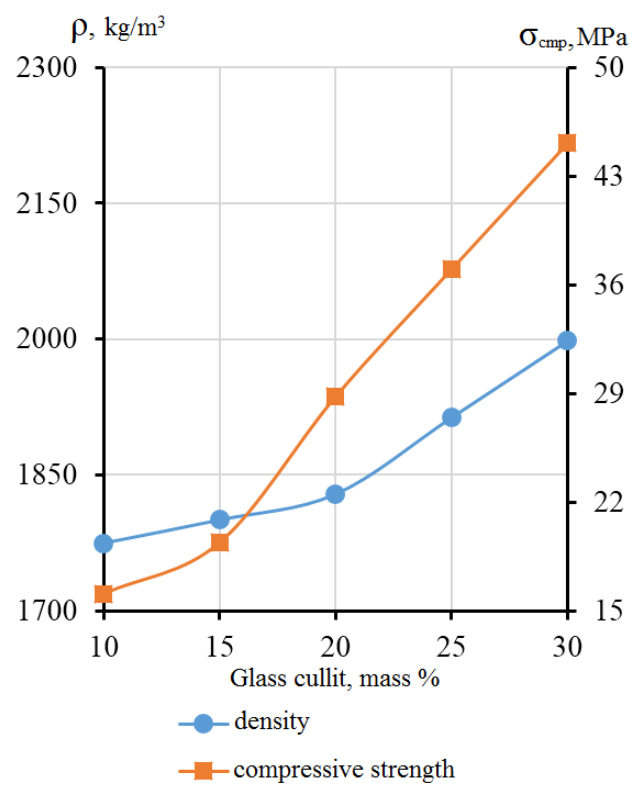

Fig. 1. The researched samples density and compressive strength.

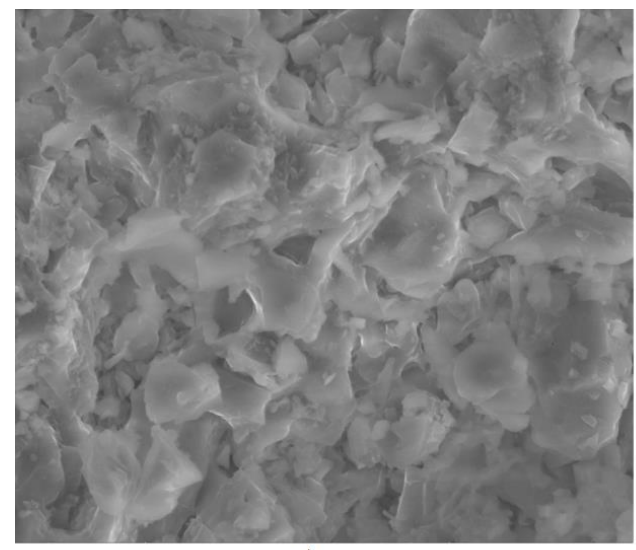

a)

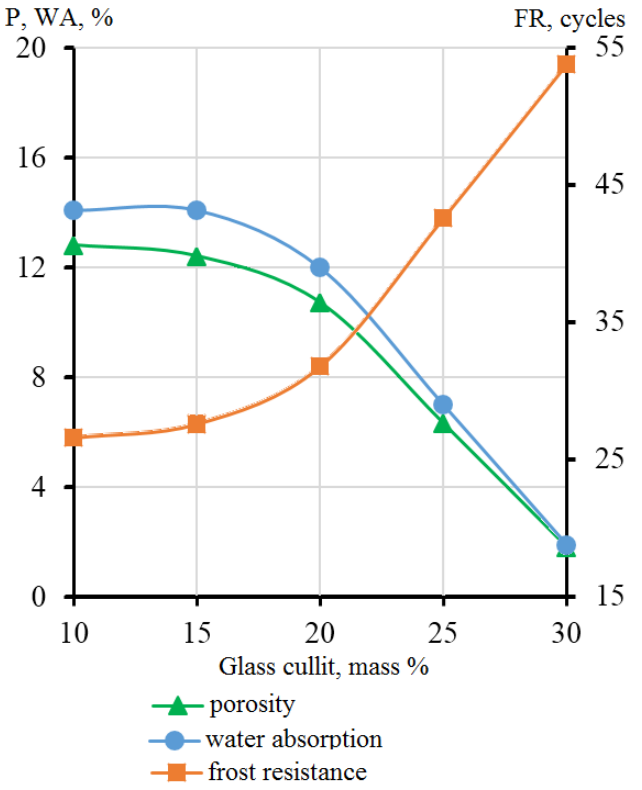

Fig. 2. The researched samples porosity, water absorption and frost resistance.

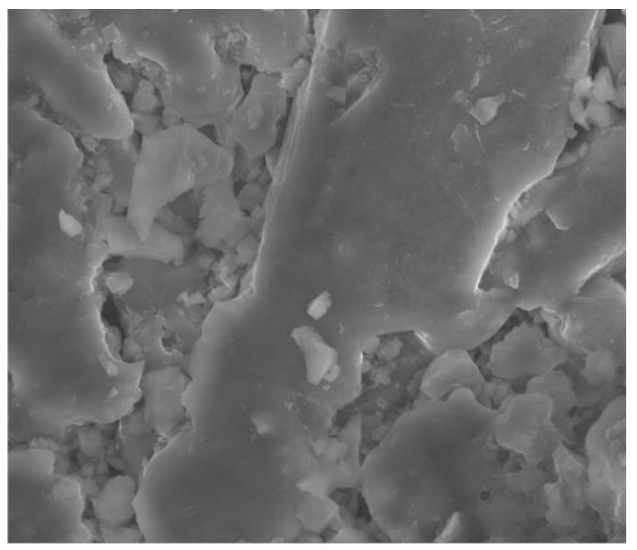

b)

\section{$30 \mathrm{mkm}$}

Fig. 3. Ceramic material structure at the introduction of 10 (a) and 30 (b) mass $\%$ of glass cullit in the charge composition (2000 times increase)

Samples toxicity test results when boric acid was introduced into the charge are shown in figure 4 . Thus the sample received when 5 mass \% of galvanic sludge (GS), 30 mass \% of glass cullit (GC) and 2.5 mass \% of boric acid (BA) were introduced into the clay can be considered ecologically safe. The results of determining physical-mechanical properties of the samples, received on the basis of compositions containing boric acid in comparison with the composition without additives are presented in the table. 




Fig. 4. Daphnia deaths dynamics in aqueous extract with various content of boric acid in the charge composition.

Table. Comparative characteristic of ceramic samples properties.

\begin{tabular}{|c|c|c|c|c|c|c|c|}
\hline \multicolumn{3}{|c|}{ Additives content, mass \% } & \multirow{2}{*}{$\begin{array}{c}\rho, \\
\mathrm{kg} / \mathrm{m}^{3}\end{array}$} & \multirow{2}{*}{$\begin{array}{l}\sigma_{\mathrm{cmp}} \\
\mathrm{MPa}\end{array}$} & \multirow{2}{*}{$\begin{array}{l}\mathrm{P}, \\
\%\end{array}$} & \multirow{2}{*}{$\begin{array}{c}\text { WA, } \\
\%\end{array}$} & \multirow{2}{*}{$\begin{array}{c}\text { FR, } \\
\text { cycles }\end{array}$} \\
\hline GS & GC & BA & & & & & \\
\hline- & - & - & 2099,4 & 14,3 & 6,9 & 7,5 & 41 \\
\hline 5 & 30 & 2,5 & 1687,0 & 29,4 & 3,0 & 3,1 & 51 \\
\hline 5 & 30 & 5 & 1865,6 & 17,7 & 2,8 & 2,9 & 51 \\
\hline
\end{tabular}

According to the table data, additives introduction stipulates the enhancing of ceramic material strength characteristics and its frost resistance and also the reduction of porosity and water absorption in comparison with ceramics produced in compliance with the similar technology but without additives introduction. It should be stated that, when glass cullit and boric acid were introduced into the charge composition, the self glazing effect is observed on the surface and in depth of the ceramic material thus additionally reducing water absorption and increasing frost resistance.

\section{Conclusions}

On the basis of the research results the conclusion can be made that the developed charge composition allows producing durable and ecologically safe ceramic material from low quality raw materials by introducing 2 types of waste including toxic galvanic sludge. Herewith considerably large amount of waste (30 mass \% of glass and 5 mass \% of galvanic sludge) is added to the charge thus stipulating its comprehensive utilization.

The production of items on the basis of the developed charge composition will allow receiving quality products under lower pressing pressure and firing temperature: $15 \mathrm{MPa}$ and $1050{ }^{\circ} \mathrm{C}$ for the developed composition in the comparison with currently produced facing ceramics under $\geq 30 \mathrm{MPa}$ and $1000-1450{ }^{\circ} \mathrm{C}$.

The new ceramic material density is lower than of the existing analogues $(1900-2200$ $\mathrm{kg} / \mathrm{m}^{3}$ for terracotta and clinker; $2400-2600 \mathrm{~kg} / \mathrm{m}^{3}$ for porcelain stoneware) thus it decreases the mass of facades and socles, paneled with that type of material, reducing the 
load on the building basement. It means that the developed material can be effectively applied in high-rise construction.

All the rest properties of the developed ceramic material allow using it for outdoor buildings facing. The glazer layer formed on the ceramic material surface is a self-cleaning surface, i.e. cleaned by the rain that can save money on washing facades and socles. It is very important especially for high building construction with large paneled areas.

\section{References}

1. M.A. Sukharnikova, E.S. Pikalov, O.G. Selivanov, V.Y. Chukhlanov, Glass and Ceramics 73 (3-4), 246-248 (2016)

2. Environment condition and population health in the Vladimir region in 2014: annual report. Issue 22 Vladimir Region Administration, environment Dpt. Vladimir: TransitX, p.120 (2015)

3. Y.I. Wiseman, A.A. Ketov, Vestnik PNIPU. Urbanistics 4, 78-75 (2011)

4. Toxicity determination method of water and water extractions from soil, waste water sediments, waste by Daphnia death and fertility change. Federal registry FR.ФP.1.39.2007.03222. Moskow: Aquaros, p.41 (2007)

5. E.S. Pikalov, O.G. Selivanov, V.Y. Chukhlanov, N.V. Chukhlanova, Ecology and industry in Russia 6, 24-29 (2017) 